\title{
The Basic Strategy and the Main Path of the Transformation of Universities
}

\author{
Xiao-Xian Lv ${ }^{1}$ \\ ${ }^{1}$ Academic Affairs Division, \\ China University Of Geosciences Great Wall College, \\ Baoding, China
}

\begin{abstract}
Under the new situation of economic development there are new requirements to the talent education in Colleges and Universities.From the perspective of government and enterprise, this paper analyzes the support strategy including policy system, operation mechanism. The colleges and universities should actively explore the path of transformation according to the four aspects of adhering to the traditional functions, establishing a new concept, strengthening the construction of talents and establishing the hybrid organization for the cooperation of production, education and research.
\end{abstract}

KEYWORD- Transformation of colleges and Universities; Combination of production, education and research; Support strategy

\section{Introduction}

There are some new requirements of the transformation of university in the era of rapid development of knowledge economy. Colleges and universities should take the opportunity to shift to applied University, strengthen the cooperation among the government, enterprises and scientific research institutes, focus on the needs of economic and social development to promote technological innovation actively. Colleges and universities also should continuously improve the scientific research ability, service ability, culture and knowledge innovation ability and promote the transformation of scientific research achievements and the development of high and new technology so that realize the leap forward development of universities and

\author{
Chun-Mei Yang ${ }^{2}$ \\ ${ }^{2}$ Management Science and Engineering School, \\ China University Of Geosciences Great Wall College, \\ Baoding, China
}

play a greater role in the construction of innovative talents training system.

\section{Analysis on the Strategy of University Transformation}

The transformation and development of colleges and universities should be based on the actual conditions of the government, enterprises and the administrative departments of education so that they can give necessary support of the policy and mechanism.

\subsection{Framework of Support Policy of Government}

\subsubsection{Grasp the Macro Perspective of}

\section{Transformation of Universities}

Government should promote the collaboration between the transformation of universities and regional industrial adjustment, take the lead to promote the University and leading enterprises to compose the research committee of collaborative innovation and expand in-depth study around the industrial layout, economic structure adjustment direction and human resources structure and other issues regularly. Government also should takes the political, economic, cultural, social, higher education development into consideration, not only pays full attention to the leading role of the development of social economic and cultural in the transformation and development of colleges and Universities, also should explore the inner link between higher education and sustainable development of economy and culture. 


\subsubsection{Establish Policy Framework to Promote the Transformation of Universities}

Government should design the top system, define the functions and positions of the government, universities and leading enterprises in promoting the transformation and development of universities at the seam time promote colleges and universities make the develop planning and implementation plans, clear work objectives and work mechanism etc., shares resource, break cooperation barriers and solve the key questions such as the division of interests and responsibilities, risk prevention and control, the integration of public welfare functions and operational functions. Government also can provide platform and policy for the cooperation among the government, school and enterprise in the policy level. By setting the boundaries of the market forces and policy, effectively avoid the colleges and universities divorced from reality.

\subsection{Improve the Cooperative Operation Mechanism by Enterprises}

2.2.1 the Construction Mechanism of Adjustment of Discipline and Specialty

Discipline and specialty is the cornerstone of talent training. Enterprises should make full use of the advantages of the market, technology and platform, according to the direction of industry development, build discipline and specialty with colleges and universities, scientific research institutions, and actively provide support for the growth of new disciplines. Enterprises should actively participate in the adjustment of discipline major in colleges and universities to provide the industrial basis and logical path for the optimization and upgrading of the discipline major and efforts to become a platform of resource supply for discipline construction. Colleges and universities give full play to the advantages and use the strength of the integration of the relevant enterprises to carry out the research of major technological innovation leading the innovation and upgrading of subject major with the breakthrough of key technology.

\subsubsection{Improve the Sharing Mechanism of the Promotion of Teaching Staff}

Enterprises and universities should establish two-way flow of teachers and training mechanism, such as the higher education teachers from colleges and universities must undergo a period of the industry practice to go to the stage. At the same time, Enterprises should establish normalized mechanism of tracking project of relative enterprise, through cultivation in Colleges and Universities and experience in enterprises teachers can track the latest development of the latest frontier to realize the close combination of theory and practice. Enterprises also should encourage senior technical personnel or business personnel of enterprises to become a part-time professor or professor of the school so that the latest development trends of the industry can be applied to the reform and perfection of the talent training mode in Colleges and universities.

\section{Path selection of University transition}

The combination of production, education and research is an effective approach for the transformation and development of colleges and Universities. The combination of production, education and research refers to the cooperation between colleges and universities and research institutes in the field of technological innovation, trying to set the education, research, development, pilot, production and sales as a whole, which is the coordination and integration of research, education and production of different social division of labor in function and resource advantage. From the perspective of the construction of the university itself, the combination of production, education and research needs to start from the following four aspects.

\subsection{Emphasize the traditional functions of university teaching and research}

Although entrepreneurial universities stress the importance of entrepreneurship, this does not mean that we can ignore the traditional functions of teaching and research, and they still play a basic role in the 
construction of entrepreneurial universities. If the single pure is to start a business and the traditional functions of the teaching and research are ignored, the ultimately entrepreneurial activity of them will become the tree without roots or the water without source.

In the process of transformation, we must realize that the ultimate goal of knowledge capitalization and industrialization is to strengthen the research and teaching ability of the University, and to cultivate more talents.

\subsection{Gradually establish a new concept of running a college}

Ideology plays an important role in the development of things, and the change of organizational ideas leads to the innovation of organizational system, and then promotes the change of behavior orientation of organization members. To establish a new concept of running a school must undergo a process of propaganda, learning and forming a common vision, which is a process for the organization members to emancipate their minds and update the concepts. This requires colleges and universities to take a variety of forms to vigorously promote the combination of production, education and research, and constantly improve the cognition of the social value of working knowledge for the organization members.

\subsection{Strengthen the construction of talent team}

The first step is to strengthen the construction of the team of application oriented teachers. The colleges and universities should strengthen the cooperation and communication between the applied teachers and encourage the strategy of bringing-in and going global so that the teachers are familiar with and master the latest trends of teaching and scientific research and industry development both at home and abroad. In addition, the teacher training activities should be held to strengthen their practical ability and promote the implementation of lifelong education. Secondly, the colleges and universities should strengthen the construction of the application oriented students. The colleges and universities should broaden the professional caliber to enhance the students' adaptability, and add practical courses to strengthen the practical link and improve students' practical operation ability. Schools and enterprises should have a more in-depth cooperation in personnel training and offer students more opportunities to participate in cooperative research programs or to practice in the enterprise, where subtends can test their research results in a real situation. More entrepreneurs should be invited to make a speech or be hired as a part-time professors in the colleges so that students and entrepreneurs have a more in-depth contact and exchange.

\subsection{Establish the hybrid organization to promote} the cooperation of production, education and research

Applied university should not only have a strong ability of knowledge innovation, but also have a sound technology transfer mechanism to transfer the value of the results to the production sector to become productive forces, which requires more close cooperation between universities and enterprise. The hybrid organization institutions combined with collaborative innovation center and production and study cooperation committee are the organization performance of the in-depth cooperation, which are also the organizational guarantee for the effective implementation of the technology transfer and intellectual property protection. Technology transfer and achievement transformation are the key to transform the scientific and technological achievements into practical productive forces. On the one hand, the hybrid organizations can transfer the scientific research achievements of the universities to suitable enterprises for the industrialization. On the other hand, the demand information of society and enterprises can be fed back to the universities by the hybrid organizations, which promotes the cooperation actively. Therefore, the technology transfer services, with responsibility for the technical contact, transfer and tracking feedback work, can be set up in the school in the process of building an entrepreneurial university. Also, it can be the third party organizations, which can be formed both spontaneously 
and under the guidance of the government. So, the hybrid organizations establish a platform for technology transfer and information exchange between schools and enterprises.

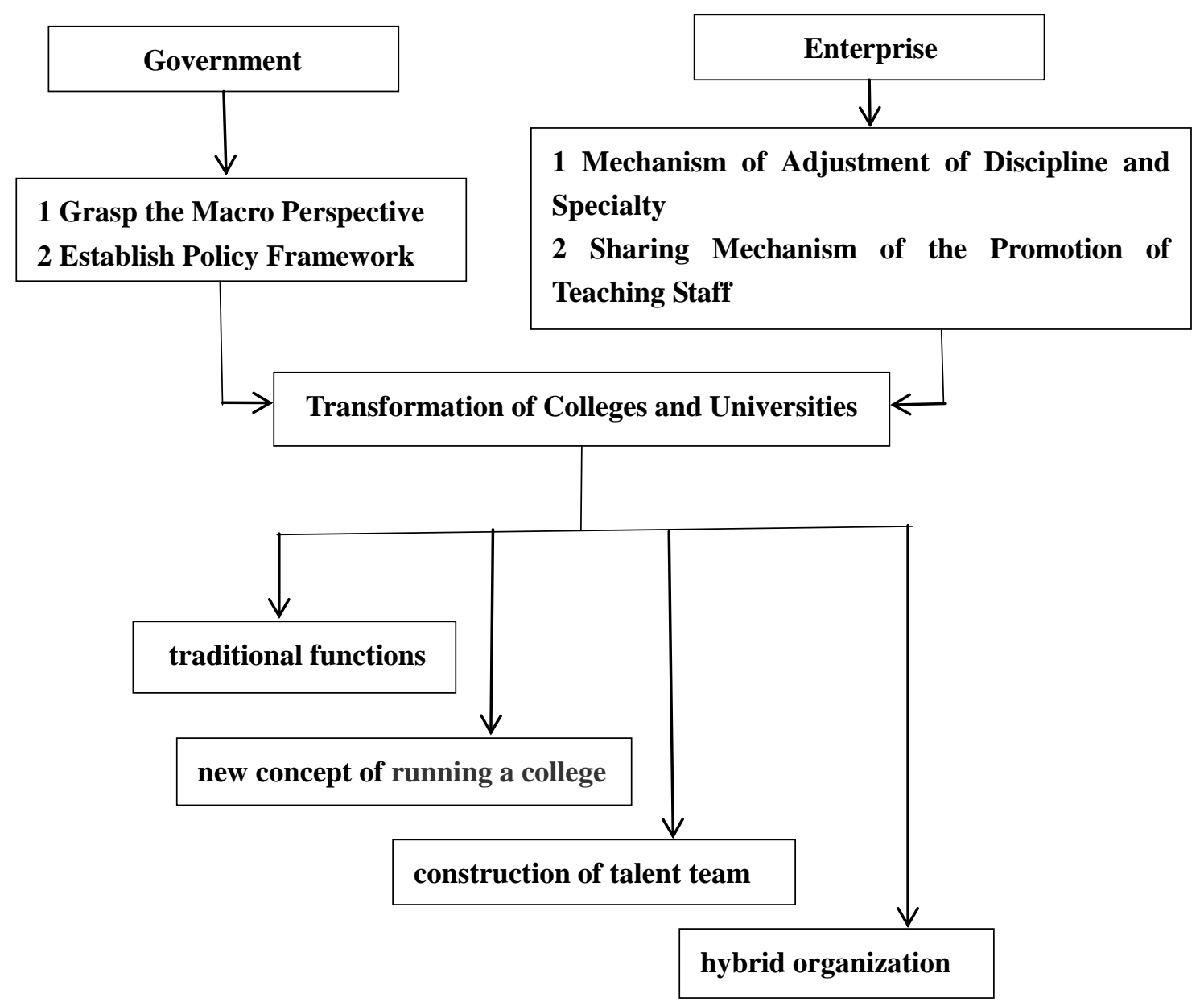

Fig: Framework of Strategy and Path

\section{Conclusion}

With the advent of the era of knowledge economy and the gradual upgrading of the industrial structure, only the positive transformation can the colleges and universities adapt to the trend of the times. From the perspective of government and enterprise, this paper analyzes the support strategy including policy system, operation mechanism. Give conclusion that the colleges and universities should actively explore the path of transformation according to their own advantages and disadvantages from the four aspects of adhering to the traditional functions, establishing a new concept, strengthening the construction of talents and establishing the hybrid organization for the cooperation of production, education and research.

\section{Acknowledgements}

This research is supported by Research and Practice of Teaching Reform of High Education in Hebei Province :Research on Transitional Development Strategies of Independent Colleges(No.SZ16132) 


\section{References}

[1] Feng Chen. Reflections on Some Problems of the Transformation and Development of Some Ordinary Undergraduate Colleges [J]. Higher education in China, 2014,12:16-20.

[2] Dianbin Qu, Yushi Zhao. Problems and Countermeasures of the Transformation and Development of Local Undergraduate Colleges and Universities[J]. Higher education in China, 2014,12:25-28.

[3] Liping Dong. Transformation and Development of Local Colleges and Universities of Applied Technology [J]. Educational Research, 2014,08:67-74.

[4] Yanlin Mou. Thoughts on Curriculum Reform in the Course of Transformation of Ordinary Undergraduate Colleges and Universities[J]. China Higher Education Research,2014,09:84-91.

[5] Zhang Yingqiang. From the Relationship Between Government and the University to See the Transformation and Development of Local Colleges and Universities $[\mathrm{J}]$. Jiangsu Higher Education,
2014,06:6-10.

[6] Zhang Yingqiang, Jiang Hualin. Reflections on Some Problems about the Transformation and Development of Local Undergraduate Colleges and Universities [J]. Modern University Education, 2014,06:1-8+112.

[7] Yao Rong. Administrative Control and Independent Change: the Institutional Logic of the Transformation of China's Dndergraduate Colleges and Universities [J]. China's Higher Education Research, 2014,11:29-34.

[8] Yao Rong. How to Move Towards Institutionalization in the Transformation of Chinese Undergraduate Colleges and Universities -Research on the Development [J]. Education from the Perspective of New Institutional Theory Based on Organizational Analysis 2015,03:1-10. 